\title{
Computational and Experimental Study of a Gas/Steam Turbine - Derivative Axial Flow Impulse-Type Hydraulic Turbine
}

\author{
Mark D. Villanueva and Jonathan C. Maglasang
}

\begin{abstract}
In large water supply system where the source is elevated, the water reaches its destination with still a lot of energy to spare. This energy can be tapped by installing appropriate hydraulic turbine along the pipeline. A prototype gas/steam turbine-derivative axial flow impulse-type was designed and simulated using the Solid Works flow simulation software. It was then fabricated and tested. The experimental results indicated that at no load condition, the rotational speed ranges from 650 to $850 \mathrm{RPM}$ depending on the water flow rate which ranges from 8.51 to 18.34 1/s. At 381 RPM, the torque was $3.05 \mathrm{~N}-\mathrm{m}$ and the efficiency was $42 \%$. The maximum efficiency occurred within the 300-350 RPM range. The flow at the exit was not much disturbed demonstrating that its installation did not hamper the supply line. It is recommended that further studies of prototypes designed on the same concept be done.
\end{abstract}

Index Terms-Axial flow, gas/steam turbine-derivative, hydraulic turbine, impulse-type.

\section{INTRODUCTION}

Bulk supply of water for household consumption, irrigation, agriculture, commercial and industrial processes usually involved large amount of water. In most cases the water from its source reaches its destination with still a lot of energy to spare. A hydraulic turbine may be installed along the supply line in order to tap and harness this source of energy for power generation. However, caution must be observed that the turbine shall be properly designed in such a way that its installation will not hamper the normal operating process of supplying water.

The only existing type of turbine that is appropriate to be installed along a pipeline is a propeller tubular type. A study was conducted of this type with variable guide opening [1]. The basic design data of tubular type hydroturbine, output power head, and efficiency characteristics due to the guide vane opening angle were examined in detail in this study using Computational Fluid Dynamics (CFD). Moreover, influences of pressure, tangential and axial velocity distributions on turbine performance were investigated by the use of the commercially available CFD codes. The results indicated that the performance of the turbine is very dependent on the flow rate, head, angular velocity, impeller size, vane inlet and outlet angles, guide vane opening, shape of the impeller and guide vanes, and number of blades. It is

Manuscript received June 10, 2014; revised October 24, 2014.

Mark D. Villanueva is with Mindanao State University, Iligan Institute of Technology, Philippines (e-mail: villanuevamarkd@gmail.com).

Jonathan C. Maglasang is with the Department of Mechanical Engineering, the College of Engineering of MSU, Iligan Institute of Technology, Iligan City, Philippines. imperative that a particular turbine must be designed for every situation. However, since it is quite costly to make a prototype and test its performance for every situation, what is being commonly practice is to utilize CFD code for the design. The use of CFD code as a tool in solving and learning insights into the complex three dimensional phenomena of hydraulic turbines is increasingly gaining acceptance [2].

\section{THEORY}

A hydraulic turbine concept which is axial and impulse type was designed based on how gas or steam turbine works. The concept was patterned after a typical steam or gas turbine engine design, i.e., having stages of stationary blades and moving blades [3], [4]. Fig. 1 shows the schematic diagram of the stator guide vanes which act as row of nozzles and the row of rotor blades. For convenience, the rotor blades are assumed to be smooth such that $\mathrm{W}_{1}$ and $\mathrm{W}_{2}$ are equal. In addition, $\beta_{1}$ and $\beta_{2}$ are also set to be equal and that the water passage area between rotor blades is made constant so that there is no pressure drop across the rotor.

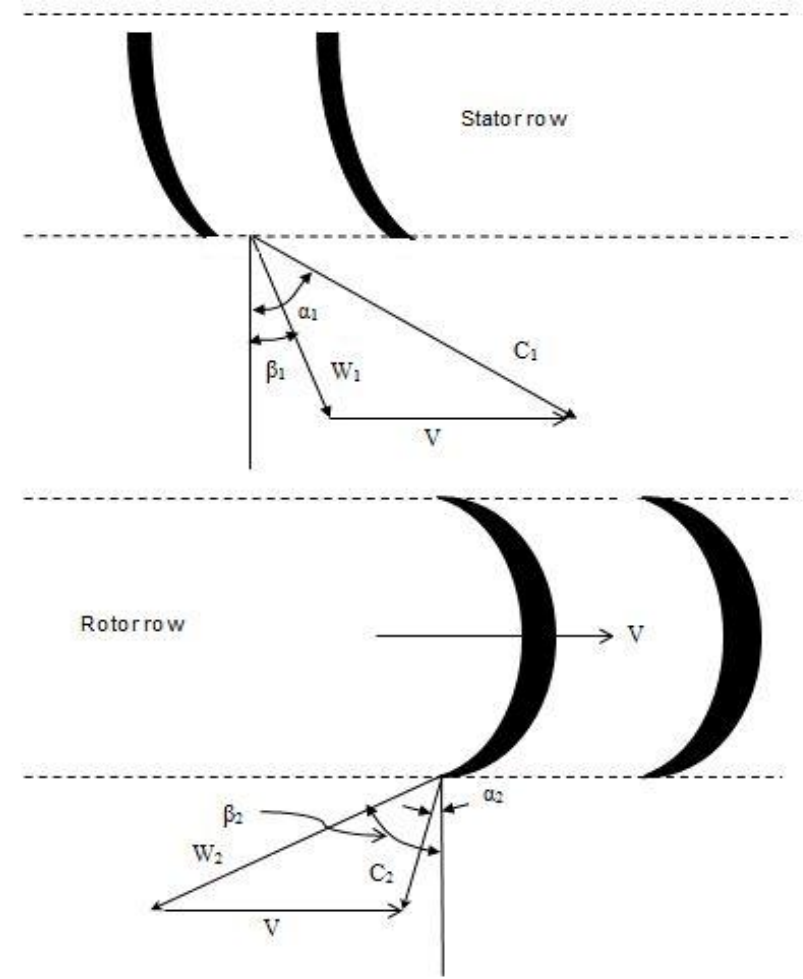

Fig. 1. Schematic diagram of the velocities in the inlet and outlet of the rotor.

The schematic diagram of Fig. 1 is reconstructed as a velocity triangle in Fig. 2. The inlet and outlet angles and 
velocities are shown with the rotor velocity as the common base.

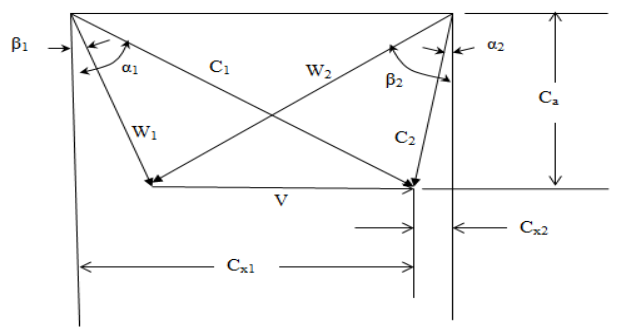

Fig. 2. Velocity triangle for an axial hydraulic turbine.

The energy transfer can be formulated from the velocity triangle of Fig. 2. Let

$E=$ work done per unit mass flow

$E=V\left(C_{x 1}-C_{x 2}\right) / g$

$E g=W / m$

$=$ work done per unit mass flow

$=V\left(C_{x 1}+C_{x 2}\right)$

$=V\left(W_{x 1}+W_{x 2}\right)$

Let

$C_{a}$ a constant and $\beta_{1}=\beta_{2}$

$$
\begin{aligned}
\mathrm{W} / \mathrm{m} & =V C_{a}\left(\tan \beta_{1}+\tan \beta_{2}\right) \\
& =2 V C_{a} \tan \beta_{1}
\end{aligned}
$$

The Diagram Efficiency can then be calculated as

$$
\begin{aligned}
\text { D.E. } & =2 V\left(C_{1} \sin \alpha_{1}-V\right)\left(1+\omega_{R}\right) / C_{1}{ }^{2} \\
& =2\left[\left(V\left(C_{1}\right) \sin \alpha_{1}-\left(V / C_{1}\right)^{2}\right]\left(1+\omega_{R}\right)\right.
\end{aligned}
$$

The maximum Diagram Efficiency can then be computed by setting the first order differential to zero as shown in the equations below.

$$
\begin{gathered}
\frac{d(\text { D.E. })}{d \frac{V}{C_{1}}}=0=\sin a_{1}-2 \frac{V}{C_{1}} \\
\frac{V}{C_{1}}=\frac{\sin \alpha_{1}}{2}
\end{gathered}
$$

From Fig. 2,

$$
C_{a}=C_{1} \cos \alpha_{1}
$$

where $C_{1}$ is obtained from (2). Sustituting into (1) and simplifying will result to

$$
\begin{aligned}
W / m= & \left(4 V^{2} / \sin \alpha_{1}\right) \cos \alpha_{1} \tan \beta_{1} \\
& =4 V^{2} \tan \beta_{1} / \tan \alpha_{1}
\end{aligned}
$$

The major differences of the hydraulic turbines and gas/steam turbines were identified and considered in the design. The orientation of the hydraulic turbine was considered in setting up since the gravitational effect of water may affect the flow pattern as it would tend to settle downward. The main reason why the hydraulic turbine was installed horizontally was that it is the position in which the maximum effect of settling down of water occurs while the rotor is rotating. It means that if it is stable in a horizontal position then it will be stable in any other positions. In the operation side, gas turbines operate at high speed with rotational speed of $12,000 \mathrm{RPM}$ or more with operating temperature of up to $1000^{\circ} \mathrm{C}$ [5]. Steam turbines have speeds higher than 6,500 RPM and operating temperature of $500^{\circ} \mathrm{C}$ [6]. In contrast, hydraulic turbines have speeds lower than 1200 RPM with operating temperature almost the same as the surrounding temperature.

\section{Methodology}

The design of the prototype started with the sizing of the prototype based on the available size of PVC pipes and source of water for the experiment, i.e., flow rate and head. The other parameters such as the inlet and outlet blade angles, number of blades of the inlet and outlet guide vanes, and the rotating impeller, their size and configuration were determined after several computer simulations.

Theoretical computations for the available power based on the head and flow rate were done. The design of the prototype as to its configuration was obtained by computer simulation using the SolidWorks Flow Simulation software [7], [8]. The prototype was then fabricated and installed at its experimental site. The installed experimental set-up was then commissioned. At this stage, alignment of the set up and adjustments were made to see to it that it ran with minimal vibrations. After commissioning, experiments then followed. Experimental data on the flow rate, torque developed, shaft angular velocity, inlet and outlet pressures were gathered. The results were then analysed and secondary data such as power generated, and efficiency were calculated and compared to the data gathered from computer simulations.

\section{COMPUTER SIMULATION}

Fig. 3 shows the configuration of the hydraulic turbine. The following design parameters were used in the design and simulation of the hydraulic turbine:

$Q=18$ liters/second $\left(0.018 \mathrm{~m}^{3} /\right.$ second $)$

Rotor outside diameter $=6$ inches $(0.1524 \mathrm{~m})$

Rotor root diameter $=4$ inches $(0.1016 \mathrm{~m})$

Mean rotor radius $=2.5$ inches $(0.0635 \mathrm{~m})$

Number of blades of inlet guide vanes $=17$

Number of blades of the rotor $=16$

Number of blades of the outlet guide vanes $=12$

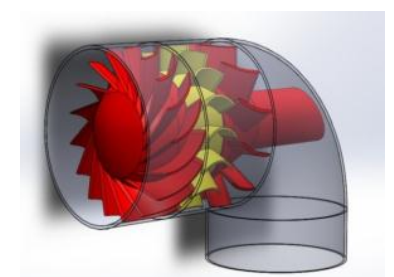

Fig. 3. Configuration of the prototype turbine.

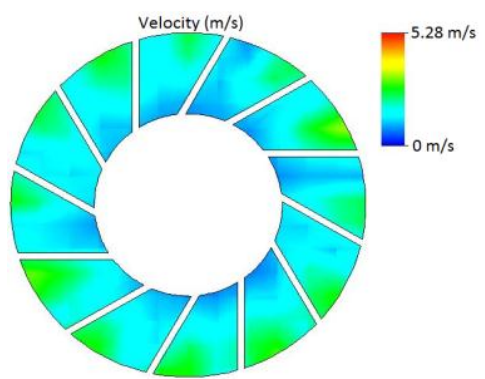

Fig. 4. Velocity profile at the front plane. 
Fig. 4 and Fig. 5 illustrate the typical velocity and pressure profile results respectively. Fig. 4 shows the increasing velocity from the center to the tip of the rotating impeller. In Fig. 5 the direction of flow is from right to left. The high pressure region is at the entrance of the static inlet guide vanes.

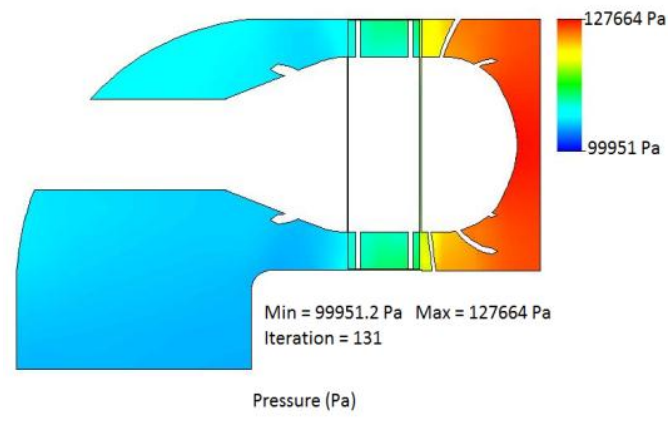

Fig. 5. Pressure profile at the right plane.

There were many computer simulations done in the finalization of the prototype configuration. Fig. 6 below is an example of a rejected configuration.

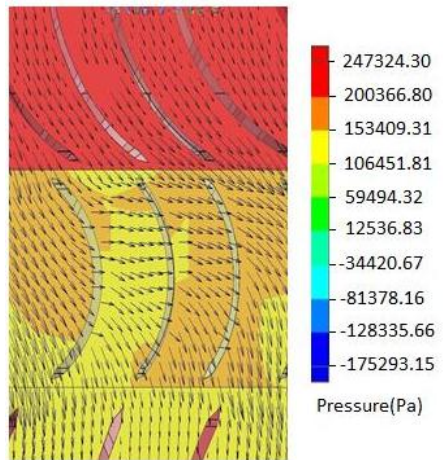

Fig. 6. Example of a rejected configuration.

The axis of the shaft of the rotating impeller as shown in Fig. 6 is in vertical position. The flow emanates from the top towards the bottom part. The color indicates the pressure distribution from the inlet (red) to the impeller (yellow orange) and then to the exit vanes (yellow). The multidirectional arrows indicate the flow trajectory, obvious in posting uneven distribution of pressure in the rotating impeller. This result suggests pressure differences which are likely to cause vibration and speed up wear and tear process of the impeller. There are also uneven trajectory flows of water across the inlet to the exit vanes as indicated by the crowding in some spots, while sparse distribution is observed in other areas.

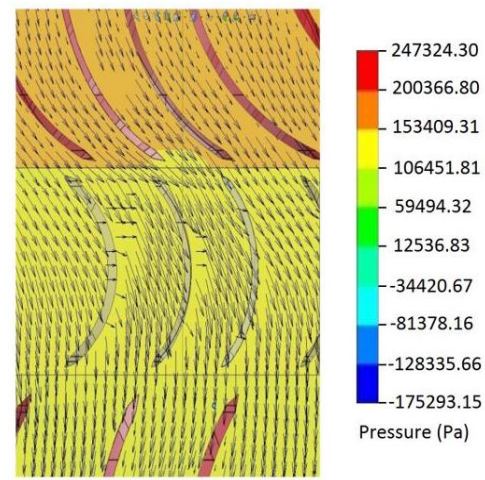

Fig. 7. Example of an acceptable configuration.
By contrast an example of a simulation where the results are acceptable is shown in Fig. 7. The pressure profile shows a uniform pressure within the inlet vanes, the rotating impellers and the exit vanes. The trajectory flows are evenly distributed specially in the rotating impeller. Based on several simulations, this type of acceptable simulation holds true for rotational speeds ranging from $150 \mathrm{rpm}$ to $800 \mathrm{rpm}$.

The velocity cut plot and flow trajectory of the acceptable configuration are shown in the following Fig. 8 and Fig. 9 below respectively.

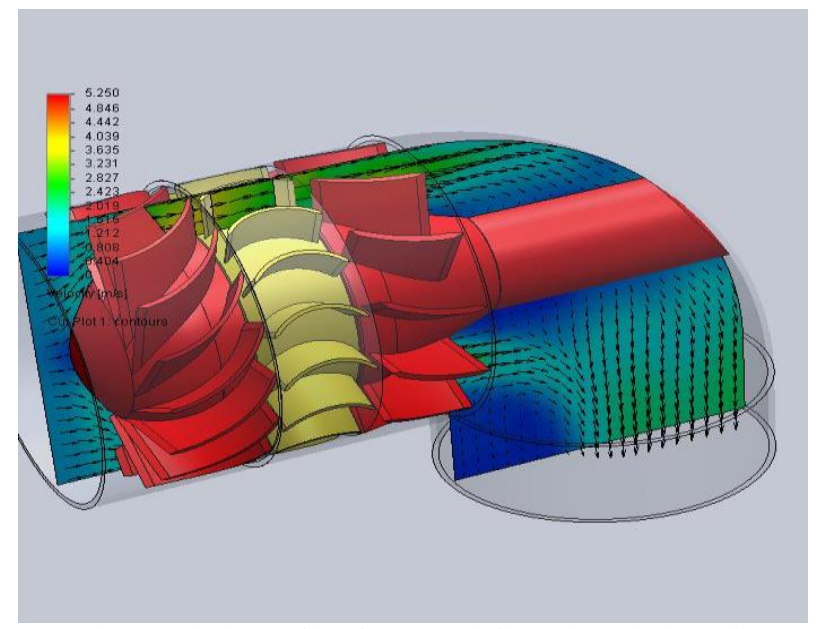

Fig. 8. Velocity profile of water as it flows through the turbine.

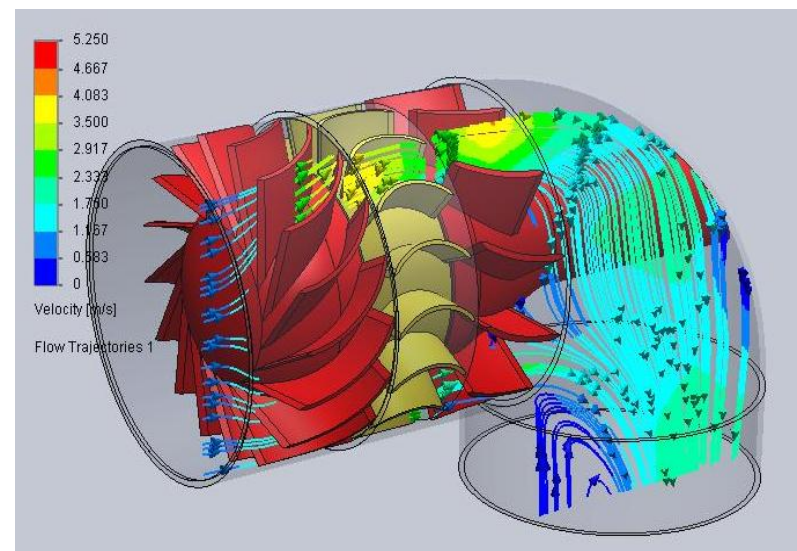

Fig. 9. Flow trajectory profile of water through the turbine.

The flow trajectory shown in Fig. 9 above indicates circulatory flows right after the curve. This is due to the presence of the curve right after the exit vanes. Circulatory flows are undesirable for these will cause resistance to the flow resulting to loss in power generated. However in this situation and with the size of the enclosing pipe, the only way to have the rotating shaft connected to the driving assembly to the generator is by extending the shaft through the curve portion of the pipeline. In large size turbine this curve maybe eliminated since enough space for the connection of the rotating shaft and driving assembly can be provided by having an enclosure. However, the enclosure provided for the driving assembly would also tend to disturb the flow trajectory resulting to loss in power generated. This is a typical example of trading off design optimization to operation accessibility. Computer simulation is very important in this situation since it will speed up the process of deciding on the best design configurations.

Fig. 10 shows the velocity and pressure profiles of the flow 
of the accepted configuration. The parameters used in the simulation are as follows:

Water Volumetric Flow $=18.34$ liters/second

Head $=1.75$ meters of water

The values of head and water volumetric flow are within the range of available water flow rates and heads in the test site.

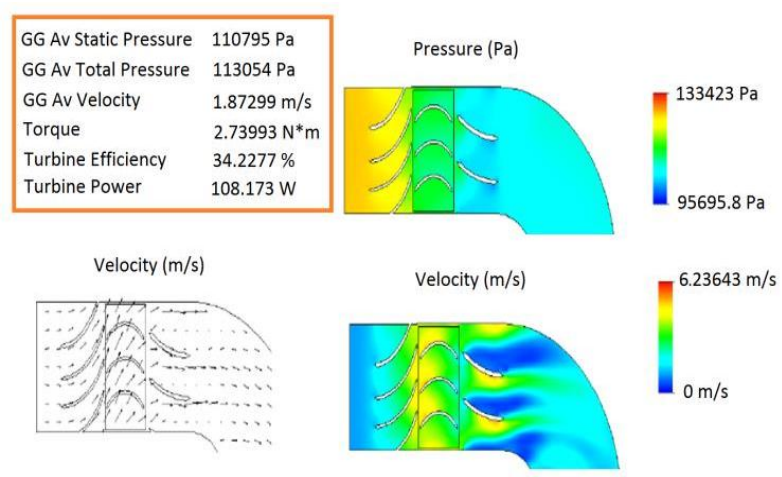

Fig. 10. Velocity and pressure profiles.

The following figures show the constructed major parts of the turbine. Fig. 11 shows the front profile of the inlet vanes. As shown there are 17 blades with the cone placed at the center. Each blade was locked in with the cone and ring enclosure. Marine epoxy was used to strengthen the connection then it was polished and finished to the desired shape. The ring enclosure was then allowed to slide through the pipe.

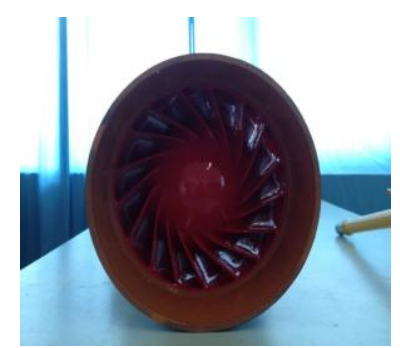

Fig. 11. Inlet guide vanes attached to the inlet cone.

The profile of the rotating impeller is shown in Fig. 12. There are 16 blades made by cutting parts of the PVC pipe. The blades were locked into a ring made also of PVC pipe material, using marine epoxy and were then polished and finished to the desired configurations. A machined metal disk was inserted into the ring and the two were connected by marine epoxy. The disk has a keyway to facilitate assembly and disassembly of the impeller to the metal shaft using a metallic key. The metal disk serves as flywheel and thus makes the rotation smooth in the event of variations of operating parameters.

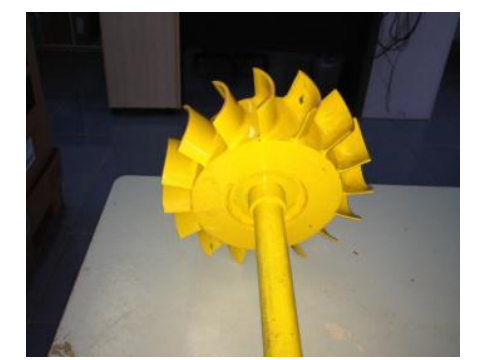

Fig. 12. The rotor of the hydraulic turbine.

Fig. 13 is the front profile of the exit guide vanes. The fabrication process is quite similar to the inlet vanes. There are 12 blades leading the exit portion of the pipe. Take note of the small pipe that is installed at the center. The pipe is intended to accommodate the shaft and bearings of the rotating impeller. The shaft bearing assembly must be water tight to avoid leakage of water through the inner portion of the small pipe. Bearings with mechanical seal were used in the assembly.

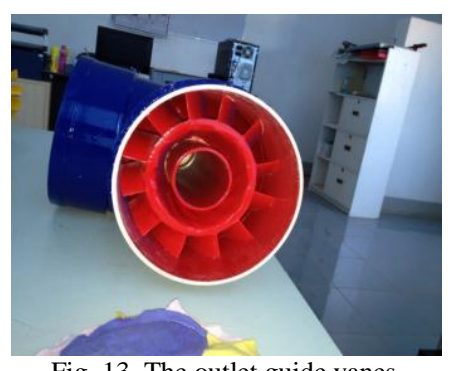

Fig. 13. The outlet guide vanes.

\section{EXPERIMENTAL RESULTS AND ANALYSIS}

Fig. 14 shows the results showing the torque decreases with increase in angular speed at constant volumetric flow and increase in both torque and RPM as the volumetric flow is increased. The maximum torque that the turbine can developed was not fully determined because the dynamometer is only capable of measuring up to $3.058 \mathrm{~N}-\mathrm{m}$ resulting to lesser data gathered on $18.34 \mathrm{l} / \mathrm{s}$ of flow rate. Based on the above trend at $18.34 \mathrm{l} / \mathrm{s}$, the torque can be further increased at angular speeds within the 250-300 RPM range.

The trend in the data shown in Fig. 15 is quite similar to that in Fig. 14. Again, based on the trend the maximum power is expected to occur at speeds within the 250-300 RPM range. Higher torque values were not obtained during the experimentations because of the limitation of the dynamometer.

The following Fig. 16 indicates that the maximum efficiency increases as the volumetric flow increases. Although the maximum efficiency was not experimentally measured because of dynamometer limitation, the trend indicates that the maximum efficiency will occur at the 300 350 RPM range.

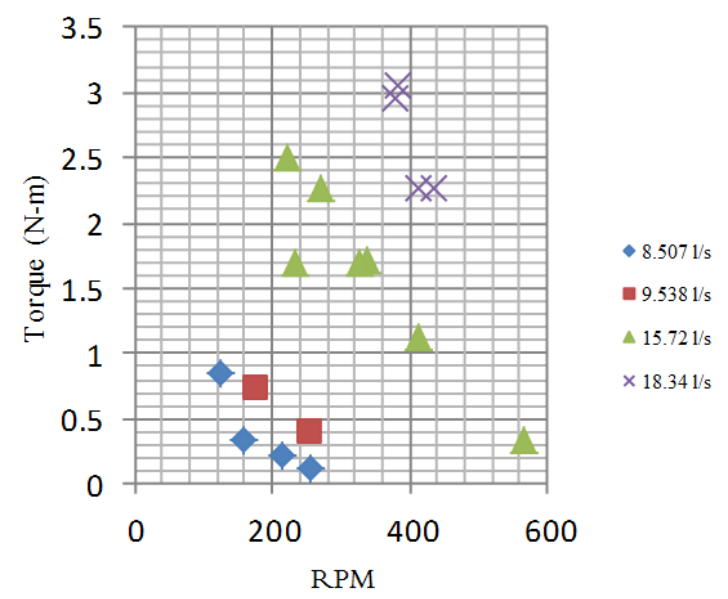

Fig. 14. Torque vs. RPM.

Fig. 17 shows a typical simulation result where the reading of the turbine power is 108.173 watts as indicated in the 
tabulated outputs. This figure is part of Fig. 10 shown previously.
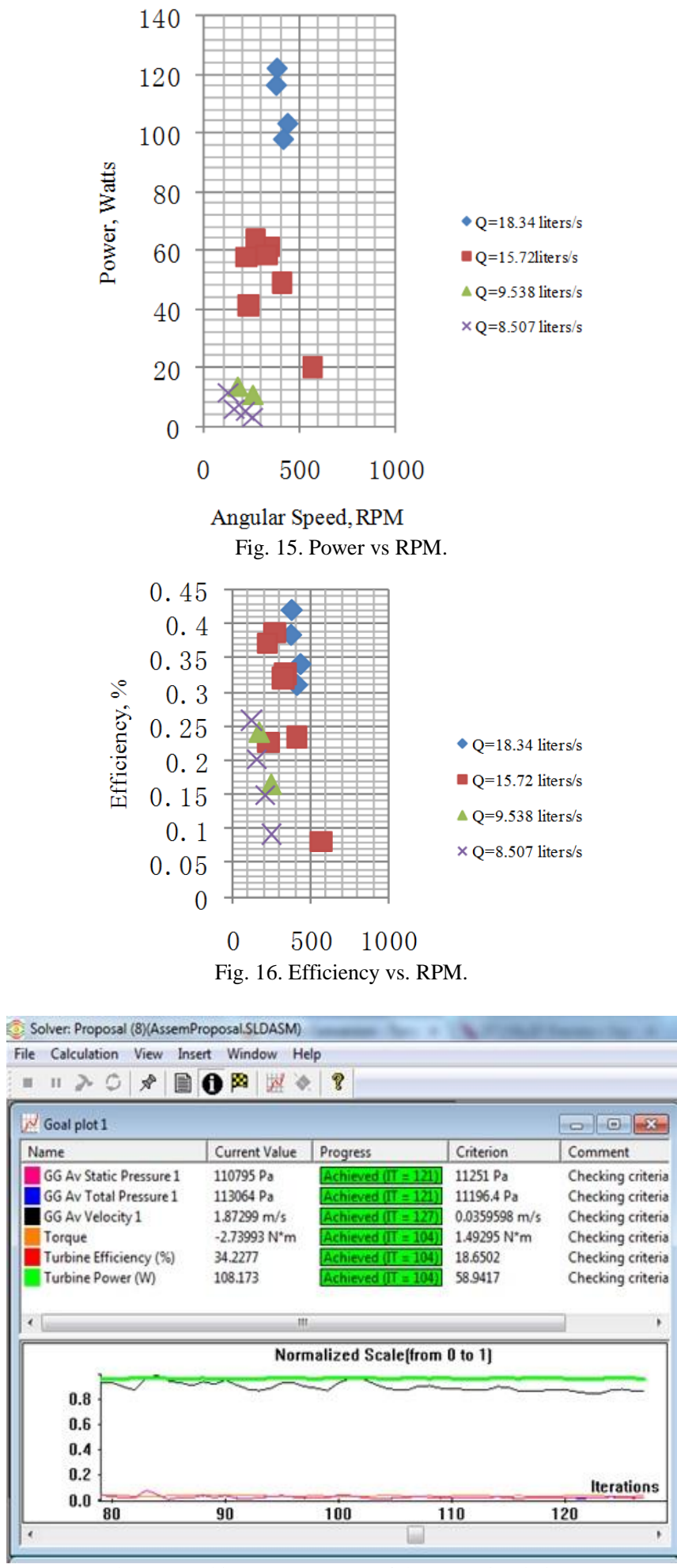

Fig. 17. Turbine power output of the CFD simulation.

Several simulations were conducted and the results similar to Fig. 17 were plotted as shown in Fig. 18. The plots of turbine power versus the angular speed of the experimental results and the CFD simulation in Fig. 18 agree very well with each other. The darkened squares and diamonds represent the power obtained from the CFD simulation at flow rates of $18.34 \mathrm{l} / \mathrm{s}$ and $15.72 \mathrm{l} / \mathrm{s}$, respectively. The undarkened triangles and circles are the experimental results for the two flow rates, respectively.

The plots of turbine efficiency versus angular speed of the experimental results and CFD simulations shown in Fig. 19 below are consistent with each other. Take note that the maximum efficiency occurs at the 300-350 RPM range.
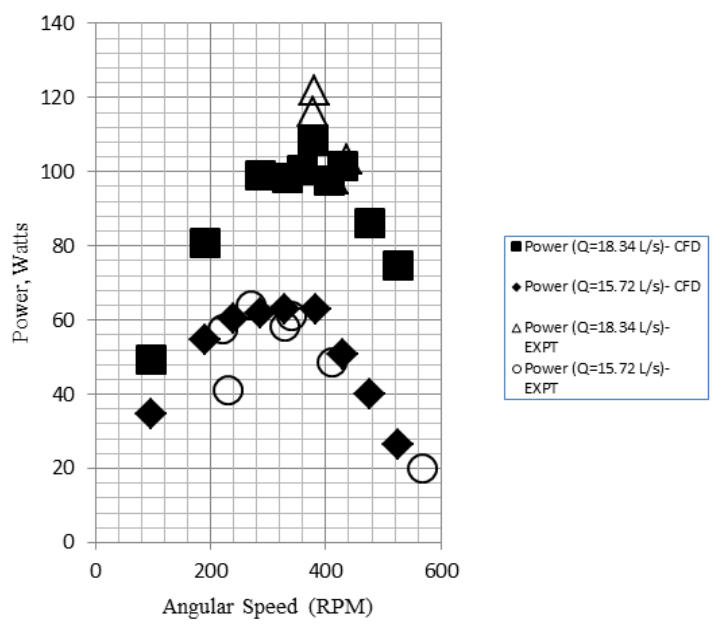

Fig. 18. Plot of turbine power vs. angular speed.

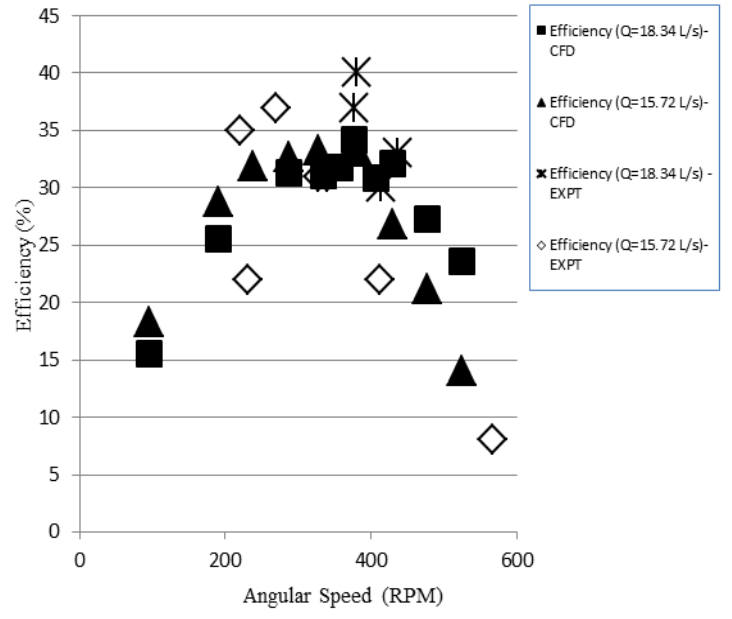

Fig. 19. Plot of turbine efficiency vs. angular speed.

\section{CONCLUSION}

A prototype axial flow impulse-type turbine was designed for the purpose of fabricating a unit that can be installed along an existing pipeline with potential for power generation. It has three major parts; the inlet vanes, the rotating impeller, and the exit vanes. The numbers of blades are 17, 16 and 12 for the inlet, rotor and exit vanes, respectively. The blade angles are $75^{\circ}$ for $\alpha_{1}$ and $45^{\circ}$ for $\beta_{1}$ and $\beta_{2}$. The pipe casing is 6 inches in diameter. The hub diameter of the rotor is 4 inches. The computer simulations using SolidWorks software showed smoothness in the flow trajectories and even pressure distribution in each of the major parts of the turbine at rotational speed ranging from 100 to $600 \mathrm{rpm}$. At angular velocity below $50 \mathrm{rpm}$ the flow trajectory and pressure distribution were unacceptable. The design is therefore applicable only to 100 to $600 \mathrm{rpm}$ range of angular velocity.

The turbine was fabricated, installed and commissioned at Rio Verde Water Consortium Incorporated Treatment Plant in Barangay Pualas, Baungon, Bukidnon, Philippines. The installation was not difficult since the set up simply attached to an existing pipeline. The turbine generated around 122 watts of power at $381 \mathrm{rpm}$ with an efficiency of $42 \%$ for a 
flow rate of $18.34 \mathrm{l} / \mathrm{s}$. It operated with very minimal vibration during the conduct of the experiments.

The experimental results agreed well and thus validated the computer simulation results leading to the conclusion that the SolidWorks software is a reliable tool for designing this type of hydraulic turbine.

This type of hydraulic turbine can tapped available potential power from flowing water used for other purposes such as for cooling of industrial equipment and water to be processed for household consumption. Instead of wasting, the available power is utilized and made useful. Hydro power is renewable and every watt it generated is a factor in reducing carbon emission and a positive step to preservation of the environment.

\section{RECOMMENDATIONS}

The following are recommended for further study, policy review and action:

1) Use the results of the study as bases in conducting assessments of existing water pipelines of industrial plants with pressure heads in excess of their operating requirements. The excess heads can be harnessed for power generation as demonstrated in the results of this study.

2) Fabrication of a turbine assembly made of metal to be installed in the main process line of Rio Verde Water Consortium Incorporated Treatment plant;

3) Evaluation of the performance of the installed turbine assembly in terms of the effect of scaling up the configurations as compared to the prototype;

4) Further studies on cavitation of this type of hydraulic turbine particularly the pressure variations that may cause vaporization of the water leading to cavitation and vibrations;

5) Formulation of a policy/regulation on the metering of generated power to the gridlines of electric power distributors This will encourage industrial plants to harness potential source of hydropower. The power generated from this source will augment their power requirements during high demand and they can sell their extra power during low demand period; and

6) Utilization of advanced materials such as composites for the vanes and rotor.

\section{ACKNOWLEDGMENT}

The authors would like to thank the Engineering Research and Development for Technology (ERDT) under the Science Education Institute (SEI) of Department of Science and Technology, Rio Verde Water Consortium Inc., and the College of Engineering of MSU-IIT for the financial and logistics support to this project.

\section{REFERENCES}

[1] Y. T. Kim, S. H. Nam, Y. C. Cho, Y. C. Hwang, Y. D. Choi, C. D. Nam, and Y. H. Lee, "Tubular-type hydroturbine performance for variable guide vane opening by CFD," New Trends in Fluid Mechanics Research, Springer, pp. 424-427, 2009.

[2] P. Drtina and M. Sallaberger, "Hydraulic turbines- Basic principles and state of the art computational fluid dynamics applications," in Proceedings of the Institution of Mechanical Engineers-Part CJournal of Mechanical Engineering Science, vol. 213, pp. 85-102 .

[3] M. P. Boyce, Gas turbine Engineering Handbook, $4^{\text {th }}$ ed., Elsevier Publishing, 2012, p. 385.

[4] A. T. Sayers, Hydraulic and Compressible Flow Turbomachines, McGraw-Hill Book company, 1990, pp. 227-2443.

[5] P. Wirkowski, "Research of variation of gas turbine engine work parameters changes equipped with changeable geometry of axial compressor flow passage," Journal of Polish CIMAC, Faculty of ocean engineering and ship technology, Gdansk University of Technology.

[6] T. Wani, B. Nivedita, and P. Hombal, "Rotor dynamic analysis of steam turbine by finite element analysis," International Journal of Research in Mechanical Engineering and Technology, vol. 3, issue 2, pp. 291-297, May-Oct. 2013.

[7] A. Sobachkin and G. Dumnov, "Numerical basis of CAD-Embedded CFD," SolidWorks, pp. 7, 2014.

[8] Dassault Systēmes-Solid Works Corporation. Instructor's guide to teaching solid works software. [Online]. Available: http://www.solidworks.com/docs/instructor_wb_2011.pdf

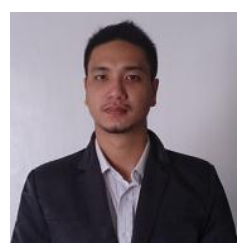

Mark Dimagiba Villanueva was born in Iligan City, Philippines on July 6, 1986. He earned his degrees of bachelor of science in mechanical engineering in 2007 and master of science in mechanical engineering in 2013 as a scholar of the Engineering Research and Development for Technology (ERDT) of the Department of Science and Technology. Both degrees were received from the MSU-Iligan Institute of Technology (MSU-IIT). At present he is taking the doctor of engineering program and majoring in mechanical engineering at the College of Engineering of MSU-IIT as an ERDT scholar.

$\mathrm{He}$ is a registered mechanical engineer and currently connected with the Research and Development and Technical Services Department of Rio Verde Water Consortium Incorporated in Cagayan de Oro City, Philippines. His major research interests are in the designing and fabrication of hydraulic turbines for micro-hydro power generations and modeling, 3D printing, and computer simulation specifically using the SolidWorks software.

Engr. Villanueva is a member of the Philippine Society of Mechanical Engineers (PSME) and Asia-Pacific Chemical, Biological and Environment Engineering Society (APCBEES).

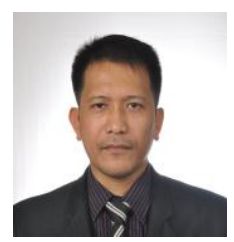

Jonathan Corbo Maglasang was born on January 4, 1972 in Cebu, Philippines. He finished his bachelor of science degree in mechanical engineering in 1994. As a scholar of the Ministry of Education, Culture, Sports, Science and Technology (MEXT) of Japan, he earned his degrees of master of engineering in aeronautics and astronautics in 2004 and doctor of engineering in aeronautics and astronautics in 2007, both from Kyushu University, Japan.

$\mathrm{He}$ is a registered mechanical engineer and presently an associate professor in the Department of mechanical engineering of the College of Engineering of MSU, Iligan Institute of Technology, Iligan City, Philippines.

His major research interests are aerospace vehicle design, biomimetic flight mechanics, rigid-body dynamics and control, applied aerodynamics, turbomachinery, and aerial robotics.

Dr. Maglasang is a member of the Philippine Society of Mechanical Engineers (PSME) and American Institute of Aeronautics and Astronautics (AIAA). 